\title{
Avatares de Prometeu: duas décadas de avaliação e regulação das políticas educacionais ${ }^{1}$
}

Silvia Cristina Yannoulas

Talita Santos de Oliveira

Universidade de Brasília

\section{Resumo}

O estudo apresenta uma revisão de literatura sobre o desenvolvimento da avaliação como instrumento fundamental na implementação de reformas educacionais contemporâneas. Primeiramente, sistematiza a utilização do conceito de Estado avaliador na literatura recente. Em segundo lugar, discute a utilização da teoria da regulação para a análise das políticas e sistemas educacionais. Finaliza comentando a utilização do conceito de Estado avaliador e da teoria da regulação pela literatura brasileira recente sobre políticas educacionais.

Palavras-chave: Avaliação. Estado avaliador. Política educacional. Regulação.

1. A elaboração do artigo contou com o apoio do Programa Observatório da Educação da Capes-Inep (Obeduc) e de Bolsa de Pós-doutoramento Sênior do CNPq. Agradecemos os comentários dos especialistas no processo de arbitragem, pois possibilitaram o aprimoramento do texto. 


\section{Avatars of Prometheus: two decades of evaluation and regulation of the educational policies}

This study presents a review of the literature about the development of evaluation as a fundamental tool in the implementation of contemporary educational reforms. Firstly, it systematizes the use of the concept of Evaluative State in the recent literature. Secondly, it discusses the use of Regulation Theory for the analysis of educational policies and systems. It concludes by commenting on the use of the concept of Evaluative State and Regulation Theory in the recent Brazilian literature on educational politics.

Keywords: Evaluation. Evaluative state. Educational policy. Regulation.

\section{Avatares de Prometeo: dos décadas de evaluación y regulación de las políticas de educacionales}

El presente estudio presenta una revisión de la literatura sobre el desarrollo de la evaluación como instrumento fundamental de la implementación de reformas educacionales contemporáneas. Primero sistematiza la utilización del concepto Estado Evaluador en la literatura reciente. En segundo lugar, discute la utilización de la teoría de la Regulación para analizar las políticas y sistemas educativos. Finaliza comentando la utilización del concepto de Estado Evaluador y la teoría de la Regulación por la literatura brasileña reciente sobre políticas educativas.

Palabras clave: Evaluación. Estado evaluador. Política educacional. Regulación. 


\section{Introdução}

A avaliação educacional sistemática constitui um dos mecanismos mais utilizados na virada do milênio para reestruturar o papel do Estado em matéria de políticas educacionais. Os especialistas concordam em apontar que a centralidade outorgada à avaliação das políticas educacionais se articula de maneira funcional com a retirada parcial das responsabilidades do Estado nas questões sociais e o incentivo à competitividade no mercado. Por meio dos sistemas de avaliação, são reorientadas as práticas desenvolvidas pelas instituições e sistemas educacionais, que tentam adapta-ser às novas lógicas imperantes, pois a não adaptação coloca em questão sua própria supervivência. No caso do ensino superior, é grande o poder de controle outorgado às avaliações, devido ao atrelamento dos resultados aos processos de reconhecimento de instituições educacionais, o credenciamento de cursos, a outorga de recursos financeiros para pesquisa, publicação, participação em eventos, entre outros aspectos. No caso da educação básica, os indicadores de desempenho escolar podem ser utilizados pelos empresários como critério seletivo na hora de contratar mão de obra, ou pelas famílias com recursos na hora de escolher o local de estudos para seus filhos.

A expressão “avaliação educacional” remete à avaliação dos alunos e à condução da relação pedagógica, que em inglês seria assesment. Mas também possui uma segunda acepção, mais recente e vinculada à preocupação com o crescimento das despesas públicas destinadas à educação e com a eficácia do gasto nas políticas educacionais, dependente da governança dos sistemas educacionais, que em inglês seria educational evaluation. (Chatel, 2011)

Na atualidade há uma sobreposição parcial dos dois registros, que acompanha a conceituação instrumental da condução da ação pública educacional pela via dos resultados. Em grande medida, isso se deve ao fato de que as novas formas de governança dos sistemas educacionais tomam por base os mecanismos e resultados das avaliações nacionais e internacionais, que mais punem do que apontam caminhos ou perspectivas para o desenvolvimento futuro.

A palavra "avatar" significa processo de transformação, metamorfose, mutação (Houaiss; Villar, 2001). Daí sua escolha para identificar o propósito do estudo. 0 Estado, em permanente metamorfose em tempos de neoliberalismo e restrição orçamentária, assume formas variadas na sua relação com a sociedade civil, redefinindo constantemente os termos da autonomia das instituições educacionais. Essas metamorfoses foram analisadas por pesquisadores das políticas educacionais, que estudaram as variadas aparências ou formatos assumidos pela avaliação nos processos de reformas educacionais, analisando suas transformações no decorrer do tempo e em diferentes latitudes.

Por sua vez, o termo "metamorfose" alude à dialética do igual e do diferente, no sentido de identificar as transformações históricas ou espaciais do formato da avaliação educacional, destacar as principais cristalizações que trazem 
simultaneamente o novo e o permanente. Conforme Castel (2010), uma metamorfose faz tremer certezas e recompõe a paisagem, porém sem constituir novidade absoluta por estar inscrita no contexto de uma mesma problematização. Assim, queremos explorar as formulações recentes em torno da avaliação educacional como maneiras por meio das quais as políticas definem e regulam a educação formal nos tempos atuais. Trata-se de uma proposta meta-avaliativa, um compromisso com o mapeamento conceitual e político em torno das políticas educacionais.

Os apontamentos anteriores explicam o texto, mas também é necessário esclarecer o contexto do artigo. 0 projeto de pesquisa que deu origem às reflexões teve por objetivo localizar e comparar a utilização do conceito "Estado avaliador" na produção científica recente (sobre o projeto, ver: Yannoulas; Souza; Assis, 2009). O projeto objetivou apontar lacunas na reflexão sobre as transformações no Estado e seus impactos nas políticas públicas, especialmente considerando a tensão entre provisão de serviços e avaliação de serviços educacionais, bem como a autonomia das instituições. Foi realizada uma procura intensiva em bases abertas (Scientific Electronic Library On Line - Scielo e Biblioteca Digital Brasileira de Teses e Dissertações - BDTD), visando localizar produções acadêmicas recentes que incluam o Estado avaliador entre suas palavras-chave. 0 período considerado incluiu duas décadas de produção científica, de 1988 a 2008. No presente texto, propomos uma releitura e ampliação desses resultados, incorporando reflexões que tomam por base a teoria da regulação.

0 propósito geral do artigo é resgatar as visões críticas sobre a ação reguladora do Estado em matéria educacional, recuperando os principais argumentos utilizados na literatura científica recente. Reconhecemos que se trata de um tema complexo, especialmente pela nossa posição necessariamente interessada ao interior do sistema educacional. Entretanto, acreditamos na necessidade de analisar criticamente o papel da avaliação na determinação e na regulação das políticas educacionais.

\section{0 conceito de Estado avaliador}

É importante situar a emergência do conceito de Estado avaliador entre os especialistas em políticas educacionais. No final da década de 1980, o interesse na questão da avaliação de políticas sociais demonstrado pelos governos neoconservadores e neoliberais de países centrais começou a ser traduzido pela expressão "Estado avaliador". Neave (1988) utilizou a expressão para chamar a atenção sobre a mudança na relação estabelecida entre o Estado e as instituições europeias ocidentais de educação superior. Outros autores, como Burton Clark e Frans Van Vught, contribuíram para o desenvolvimento inicial do arcabouço 
analítico destinado a entender a educação superior em tempos de neoliberalismo (sobre a história do conceito, ver Enders, Van Vught, 2007).

Segundo Neave (1988), o Estado avaliador consiste numa racionalização e numa redistribuição geral das funções (e dos poderes) entre o centro e a periferia, de maneira tal que o centro conservaria o controle estratégico global por meio de mecanismos políticos constituídos pela definição de metas para o sistema educacional ou para um nível do sistema, e o estabelecimento de critérios e processos de controle de qualidade do produto. Poucas áreas de atuação do Estado escapam ao controle exercido pelo Estado avaliador, pois o resultado da avaliação é utilizado para distribuir os recursos humanos e financeiros entre as instituições que oferecem um serviço. 0 conceito formulado por Neave está de acordo com um modelo de gestão pública que se orienta por resultados atingidos pela instituição potencialmente beneficiária dos recursos financeiros. 0 foco do controle por parte do Estado avaliador não se concentra nos processos, mas nos resultados. 0 novo tipo de controle realizado pelo Estado permitiu a adaptação gradativa das próprias instituições de educação superior europeias, introduzindo os valores e a lógica capitalista racional própria do setor produtivo.

Elliot (2002) também utilizou o conceito de Estado avaliador para analisar a realidade do Reino Unido na virada do milênio. 0 autor pontuou que o Estado abandonou progressivamente seu papel de provedor de serviços públicos para erigir-se como o ente regulador do mercado educacional privatizado por excelência. Isso significa o abandono do conceito de educação como bem público, necessário para o desenvolvimento de uma ordem social justa e democrática. A relação entre o Estado e essas entidades se fundamenta no princípio da responsabilidade contratual, e são criadas instâncias visando ao exercício dos procedimentos de auditoria e avaliação externa.

No contexto da literatura europeia, a francesa Van Zanten (2011) diferencia o modelo do quase-mercado e o modelo do Estado avaliador. Opondo-se a uma interpretação homogênea e monolítica, a autora destaca que observações mais detalhadas mostram a influência convergente da eficácia como princípio organizador da avaliação dos sistemas educacionais, porém com implementação de diversos modelos. Assim, por exemplo, alguns autores gostam de distinguir uma via neofordista (dos governos da nova direita, orientada pela flexibilização, pela privatização, pelo individualismo competitivo, pelas lógicas de mercado), de uma via pós-fordista (dos governos modernistas de esquerda, orientada pela focalização em setores chave, que investe em capital humano e na pesquisal.

Afonso $(1999,2001)$ também realiza a mesma distinção conceitual. Com a crise do Estado provedor, assistimos ao surgimento dos tipos de propostas: o Estado avaliador associado ao neoconservadorismo lque propõe uma intervenção mais forte do Estado no controle da oferta de serviços educacionais) e o quase-mercado avaliador lassociado ao neoliberalismo, que propõe a regulação dos serviços pelo mercado e menos intervenção do Estado). 
Para Afonso (1999), a expressão Estado avaliador significa que o Estado adotou um ethos competitivo, importando para o domínio público modelos de gestão privada cuja ênfase é posta nos resultados ou produtos. Para Afonso, o aparecimento do Estado avaliador não se constitui num fenômeno que pode ser atribuído exclusivamente às modificações do final do século XX. Esse fenômeno se fez presente desde o momento em que os governos assumiram a tarefa de financiar a educação, bem como a de definir as normas dentro das quais se desenvolvem tais instituições.

Na América Latina, a partir da década de 1980, surgem as agências nacionais de credenciamento e avaliação institucional em matéria de educação superior (sendo o caso brasileiro precursor), manifestação latino-americana das tendências europeias de constituição do Estado avaliador. Mas os contextos de aplicação são muito diferentes, pois, se na Europa o movimento pela centralidade da avaliação como mecanismo de governança significou uma diminuição relativa do controle administrativo, no contexto da América Latina o deslocamento pareceria ser ao contrário: a avaliação permitiu maior controle sobre as instituições lespecialmente no caso das instituições de educação superior com larga tradição de autonomia universitária).

Segundo Brunner (1990), os desafios em matéria de educação superior para os Estados latino-americanos teriam aumentado após reinstalação das democracias, pois a educação superior massificou-se e diversificou-se num contexto de restrições orçamentárias próprias dos tempos neoliberais e, ao mesmo tempo, num contexto de liberdade e promoção de direitos civis e políticos. Essa situação causou a crise dos antigos modelos de relacionamento entre Estado e sociedade civil em matéria de educação superior. 0 Estado abandonou parcialmente suas antigas funções educacionais e passou a exercer, em maior medida, a função de regular a educação superior, por meio de avaliações e credenciamentos periódicos. Essa nova modalidade de regulação redefiniria e ampliaria o papel dos intelectuais e acadêmicos na própria condução da educação superior, pois eles seriam a peça chave dos processos avaliativos e autoavaliativos, por meio da participação nos organismos de governo universitário e na formulação de políticas científico-tecnológicas.

Assim, o Estado avaliador presente na América Latina surgiu associado à massificação e à diversificação, bem como ao controle de gastos e resultados, pretendendo assegurar mais eficiência e manutenção do controle sobre aquilo que considera qualidade superior e competitividade. Possui predominantemente uma função técnico-burocrática, com uma finalidade economicista. Como consequência, os tipos de avaliação realizados revelam algumas tendências semelhantes: são externas, realizadas por entes externos à instituição, e são exógenas, decididas fora da instituição (em contraposição às avaliações internas e endógenas); são somativas, e não formativas; estão focadas nos resultados, e não nos processos pedagógicos ou na efetividade social das políticas educacionais; são realizadas 
majoritariamente ex-post e direcionadas a estimular a competitividade das instituições de educação superior que compõem o quase-mercado educacional. ${ }^{2}$

\section{Ampliando a revisão de literatura: a teoria da regulação}

Outro enfoque para a mesma problemática pode ser dado ao se observar a educação pública como parte da administração pública. Para Dutercq (2011), a história da administração da educação faz parte da história da administração pública, com um modelo construído na primeira parte do século $\mathrm{XX}$, baseado originalmente na organização hierárquica taylorista e na racionalidade burocrática. A partir do final do século $X X, 0$ modelo original foi progressivamente sendo substituído por um modelo de gestão participativa e com base na racionalidade instrumental. Esse modelo instrumental se organiza em torno dos seguintes princípios norteadores: eficácia dos serviços públicos e dos investimentos que thes são concedidos, melhoria do serviço aos usuários, rigor da gestão e transparência na ação. Como consequência direta da implantação desse segundo modelo, foi estabelecida uma "cultura da avaliação" (Dutercq, 2011, grifos do autor). Os referenciais da ação administrativa atual são híbridos, feitos de conhecimentos administrativos, empresariais, políticos e pedagógicos oriundos dos diferentes universos que compõem a administração da educação. Entretanto, a avaliação é onipresente.

Pons (2011) também destaca o caráter híbrido do novo modelo. 0 autor entende que a administração da educação não passou totalmente de um modelo para outro, de uma regulação fundada no controle de conformidade e obrigação de meios (regulamentação) para uma regulação centrada na obrigatoriedade de resultados (avaliação). Para a melhor compreensão dessa heterogeneidade, procuramos auxílio na teoria da regulação.

0 termo "regulação", mais utilizado para caracterizar as transformações recentes dos sistemas educacionais, guarda semelhanças com o conceito de Estado avaliador, por compartilhar a origem europeia e o espírito crítico na maneira de observar as políticas educacionais em tempos neoliberais. Os autores regulacionistas consideram que as novas formas de gestão e financiamento da educação são soluções técnicas e políticas para a racionalização dos recursos existentes e a transparência na sua utilização eficiente. Os regulacionistas compreendem a política educacional, conforme indicado por Oliveira (2011), como resultado da ação de grupos de interesse, visibilizando o próprio processo de construção das políticas.

A teoria foi concebida em meados da década de 1970, dentro do Centre pour

2. A classificação das funções e tipos de avaliação pode ser consultada em Dias Sobrinho (2003) e Allal (2011). 
la recherche économique et ses applications (Cepremap). Michel Aglietta (1982), economista francês, é considerado na literatura econômica internacional o fundador da Escola Francesa da Regulação. Sua obra publicada em 1976, Régulation et crises du capitalisme, sentou as bases para o desenvolvimento da escola. Os regulacionistas passaram a designar "crise da regulação" ao processo de crise do sistema vigente, evidenciando a desarticulação de uma fase de funcionamento duradoura (de um padrão de regulação) e a incipiente constituição de uma nova fase de expansão capitalista, que geraria necessariamente uma nova estrutura capaz de recriar as bases para outra regulação. Tendo o fordismo se centrado na hegemonia da relação salarial sobre as demais formas institucionais, uma nova fase de expansão capitalista seria consequentemente acompanhada pela substituição da forma institucional até então dominante: a relação salarial foi perdendo espaço para a moeda.

Segundo a abordagem regulacionista, o capitalismo é um sistema naturalmente instável, sujeito a crises cíclicas. Porém, ele consegue se reproduzir durante determinado período, através da criação de um aparato regulatório que, uma vez aceito pelos agentes econômicos, tende a agir de forma anticíclica. Outro conceito fundamental é o de "modo de regulação", entendida como um conjunto de leis, valores e hábitos que medeiam a relação com o regime de acumulação e mantém a coesão social.

Para Oliveira (2005), o debate sobre a regulação das políticas educacionais é consequência do ciclo de reformas educacionais iniciadas na década de 1990. Embora o termo regulação tenha sido utilizado na economia e na sociologia desde seus primórdios, ele se consolida a partir dos processos de privatização no contexto do modelo neoliberal. No caso da privatização de empresas estatais responsáveis pelos serviços prioritários ou essenciais lenergia, alimentos, comunicação, entre outros), foram criadas agências de regulação para controlar o atendimento às demandas da população. Esse tipo de regulação foi objeto de grandes discussões políticas e econômicas (no Brasil, foi criada a Associação Brasileira de Agências de Regulação).

Oliveira (2005) observa que o interesse na regulação das políticas educacionais é relativamente recente, porém gradativamente crescente, com um número significativo de autores que procuram compreender se estamos diante de uma nova organização das relações entre Estado e sociedade, em que os tradicionais papéis são revistos. Contudo, a autora observa que, no âmbito educacional, esta discussão ainda se encontra restrita aos meios acadêmicos.

Conforme podemos deduzir da consulta aos dicionários especializados, é ampla a gama de estudos e pesquisas correlatas à problemática da regulação educacional: administração educacional, avaliação de políticas educacionais, tensão entre centralização e descentralização, eficácia dos sistemas educacionais, relação entre Estado e educação, instrumentos da política educacional, comparação entre sistemas educacionais, políticas educacionais, reformas educacionais, autonomia 
dos estabelecimentos, entre outros verbetes de consulta obrigatória para se compreender a relação entre sociedade, Estado e educação na virada do milênio.

Maroy (2011a) entende que, se o termo regulação é utilizado com relativo sucesso, também é grande a polissemia que o acompanha. Inicialmente utilizado com um sentido funcionalista lequilíbrio dentro de um organismo mecânico ou vivol, após as crises de legitimidade dos Estados de providência, o termo passou a ser reconsiderado, abandonando o sentido anterior de regulamentação pelo poder público para passar a nomear as novas formas de intervenção e papéis do Estado em contextos de governança - não mais de modo funcionalista, como propriedade ou função do sistema educacional (regulamentação), mas como um complexo processo, dinâmico, contraditório, incompleto, resultante de uma multiplicidade de ações em um campo específico (a educação entre eles).

Maroy (2011b) destaca a existência de um novo modo de regulação pósburocrático, com fundamento na avaliação, mas distingue duas variantes ou modelos de governança possíveis, como o fazem outros autores já mencionados: - Estado avaliador (governança por resultados) e o quase-mercado. No primeiro caso, os profissionais dos estabelecimentos de ensino são estimulados a melhorar a qualidade pela obrigação de submeter suas práticas a procedimentos de avaliação. 0 desenvolvimento da regulação pela via da avaliação estabeleceria uma mudança na maneira de controlar o trabalho docente. No caso da regulação pelo quase-mercado educacional, estrutura-se como função do Estado a de oferecer informação relevante e pertinente à livre escolha dos serviços educacionais pelos usuários. Ambos os entendimentos desse novo tipo de regulação opõemse ao modelo anterior, burocrático-profissional, por isso são denominados pósburocráticos: não encontram sua legitimidade na racionalidade ou na lei, mas nos resultados e na eficácia (racionalidade instrumental, contrária ao engajamento cívico e solidário).

Para Dale (2011), a natureza e o significado da regulação terão sofrido mudanças nos últimos anos, passando do que tem sido apreendido como uma "forma de regulação determinada por regras", que opera a priori, por meio dos inputs - isto é, das normas, orientações, recursos, programas fornecidos ao sistema educativo, para uma "forma de regulação determinada por objetivos", que atua a posteriori, baseada em determinadas realizações (outputs) do sistema. A base da regulação reside nos resultados (outcomes) determinados para o sistema. Assim, os resultados requeridos do funcionamento dos sistemas educativos devem ser traduzidos em desempenhos/produtos/saídas imediatos exibidos pelas instituições educacionais e perante os quais estas serão avaliadas. Dale argumenta que a agenda supranacional para educação e formação se constitui já como parte desta última forma de regulação e que as avaliações do tipo dos estudos Pisa (Programme for International Student Assessment) representam uma ilustração desse mecanismo de controle de resultados. 


\section{Reformas educacionais, regulação e Estado avaliador}

Cabe realizar breves considerações sobre o desenvolvimento histórico da relação entre sociedade, Estado e educação, pela sua relação direta com a questão da governança e regulação dos sistemas educacionais. Green (2011) aponta que a melhor forma de compreender a criação dos sistemas educacionais é considerála parte do longo processo de construção dos Estados europeus (do século XVIII ao início do século XX). No século XIX, as redes de escolas elementares foram consolidadas com a ajuda do Estado, e progressivamente a gratuidade do ensino e a escolaridade obrigatória foram estabelecidas, e as escolas técnicas proliferaram para responder às demandas do novo modelo de produção taylorista-fordista. A escolarização tornou-se mais regrada, organizada hierarquicamente por idade, num sistema no qual os diferentes elementos estavam sistematicamente entrelaçados. 0 controle desse sistema passou cada vez mais para as mãos dos Estados, ainda que sempre tenham sido registrados questionamentos e tensões, especialmente com a Igreja.

No início do século XX, o controle dos Estados europeus em matéria educacional aumentou, enquanto os sistemas se foram fortificando e incluindo novos níveis e modalidades. Entretanto, os debates sobre o papel do Estado não se apaziguaram, e as críticas foram formuladas por diversos atores e setores políticos no decorrer da segunda metade do século XX. Os movimentos de esquerda questionavam a persistência da desigualdade educacional conforme a classe social; os movimentos feministas e raciais, conforme o gênero e a raça/etnia, entre outros. A nova direita, apoiada pelas recomendações dos organismos internacionais, propiciou a privatização e a constituição de um quase-mercado educacional: são mercados porque substituem o monopólio dos fornecedores do Estado por uma diversidade de fornecedores independentes e competitivos; são quase porque diferem dos mercados convencionais em aspectos importantes (sobre a questão, ver: Afonso, 1999). Finalmente, no final do século $X X$, a internacionalização das políticas educativas diminuiu o controle dos Estados sobre os sistemas educacionais. Nesse aspecto, as avaliações desenvolvidas pela OCDE (Organisation for Economic Cooperation and Development) são exemplares.

Na América Latina, os contornos da nova regulação das políticas educacionais assumem características específicas, as quais merecem menção. Krawczyk e Vieira (2012) discorrem sobre as semelhanças e diferenças das reformas educacionais empreendidas por países latino-americanos, especialmente considerando Argentina, Brasil, Chile e México nos anos de 1990. Especificidades e particularidades das concretizações nacionais das reformas educacionais estimuladas no contexto da mundialização são tratadas considerando a historicidade inerente a cada caso. Mas também são abordadas as características comuns no que se refere ao processo de regulação política e à estratégia de mudança, aos câmbios estruturais na organização e na gestão dos sistemas educacionais (organicidade do sistema educacional), e ao 
papel da avaliação na reconfiguração da relação sociedade, Estado e educação.

Essa transformação está vinculada ao novo modelo de integração social vigente, que desmonta o projeto solidário próprio do Estado de bem-estar e do desenvolvimento keynesiano e rearticula os três elementos sob a perspectiva da mundialização e da competição no novo estágio de acumulação capitalista lque acentua as desigualdades). No caso da América Latina, esse processo do final do século XX deve ser especificado: os Estados de bem-estar não tinham atingido o mesmo grau de expansão e consolidação quando comparados com os europeus, e grande parte dos países estava passando por um processo de democratização após longas ditaduras militares.

Conforme Krawczyk e Vieira (2012), reconhecendo as especificidades apontadas e as complexidades inerentes à historicidade de cada país, é possível observar semelhanças nas alterações do modo de regulação na América Latina, com a presença de uma matriz pós-burocrática de coordenação das políticas educacionais, nas quais o controle hierárquico é substituído pelo autocontrole, a obrigação de meios pela obrigação de resultados, a regulamentação pela avaliação. A reforma global é substituída por micromudanças induzidas do centro para a periferia do sistema educacional, que possuem três elementos destacados: a descentralização da gestão do sistema educacional, a incorporação da gestão privada na gestão pública, a autonomia institucional como capacidade de administrar os problemas e captar recursos, combinada com a (co)responsabilização dos indivíduos e mobilização da comunidade para o provimento e a qualidade da educação escolar ${ }^{3}$.

Sistematizando as semelhanças nas reformas educacionais latino-americanas, Duarte (2010) propõe a existência de três gerações de reformas:

- um primeiro movimento ou geração de reformas, que focou sua atenção na ampliação de acesso/cobertura (no caso do Brasil, universalização do ensino fundamental, à diferença dos outros países analisados, que focaram na expansão do nível médio) e, paralelamente, na descentralização (transferência de responsabilidades e recursos);

- um segundo movimento ou geração de reformas, reforçando modos de controle e responsabilização das escolas e seus professores por meio dos resultados educacionais (criação dos sistemas centralizados de avaliação, visibilização dos resultados e desempenhos educacionais; estabelecimento de parâmetros curriculares de aplicação obrigatória em território nacional, que padronizam as práticas docentes); e

- um terceiro movimento ou geração de reformas, que buscou redefinir as relações entre responsabilidades públicas e direito à educação, enfatizando as questões relativas à participação democrática e ao controle social das políticas

3. As autoras destacam a especificidade do caso brasileiro, pois a histórica pouca responsabilidade do Estado com a provisão de educação diferencia a implementação do novo modelo. (Krawczyk; Vieira, 2012, p. 151) 
educacionais (com duas consequências importantes: criação de instâncias colegiadas e fortalecimento da figura do diretor ou diretora como gestor ou gestora, e não como professor ou professoral.

\section{Estado avaliador e regulação à brasileira}

A conceituação de Estado avaliador e de regulação educacional presente na literatura especializada é marcada pela introdução de mecanismos de mercado nas políticas educacionais, segundo os quais o controle sobre os resultados é subordinado a mera lógica burocrática, tecnicista e economicista. Pode-se observar ainda que as práticas avaliativas exercidas pelo Estado estão conformadas pelas orientações dos organismos internacionais, principalmente pelo Banco Mundial. Essas orientações estabelecem critérios de avaliação voltados para produtividade, rentabilidade e menor custo, as quais impactam de maneira negativa o trabalho docente (sobre o assunto, ver os trabalhos de: Yannoulas; Souza; Assis, 2009; Duarte, 2011).

Sousa (2003) e Sousa e Portella (2003) utilizam o modelo de quase-mercado para interpretar a aplicação, na gestão dos sistemas educacionais, dos princípios e valores da iniciativa privada, característica do Governo FHC. Para os autores, a avaliação é um processo capaz de direcionar projetos e ações, trazendo como consequência a reprodução e intensificação das desigualdades educacionais e sociais. Medidas tais como a privatização das empresas estatais, a desregulamentação da economia, tendo por escopo estimular os investimentos privados, a realização de parcerias com o setor empresarial para ampliação da oferta de serviços públicos e o fortalecimento do papel regulador/avaliador do Estado caracterizam essa tendência.

É principalmente na análise da educação superior que o conceito Estado avaliador se tem expandido. A avaliação da educação básica como mecanismo regulador da política educacional assume características e contornos específicos, principalmente devido ao fato de estar atrelada ao direito à educação e à obrigatoriedade escolar. Os efeitos perversos da regulação transnacional, consequência da emergência e difusão do Pisa, foram examinados detalhadamente por Carvalho $(2009,2011)$. Existem características semelhantes na aplicação de processos de avaliação como instrumentos de controle da educação básica e da educação superior, porém entendemos que a longa história da obrigatoriedade escolar no caso da educação básica, e da autonomia universitária no caso da educação superior latino-americana, estabelece contextos diferentes para o exercício desse controle 4 .

A discussão sobre a obrigatoriedade do nível superior de educação ainda não

4. Dupriez (2011) aborda a história da autonomia dos estabelecimentos escolares de educação básica. Vaccarezza (2006) e Cunha (2006) abordam a questão da autonomia universitária e autonomia científica. 
atingiu plenamente os sistemas educacionais latino-americanos, entretanto a autonomia universitária remonta aos inícios do século XX. Com relação ao caso brasileiro, faz-se necessário um esclarecimento adicional: a educação básica pública não depende prioritariamente da esfera federal de governo (sendo responsabilidade dos Municípios e das outras unidades da Federação), mas sim a educação superior pública, o que estabelece poderes regulatórios diferenciados para cada nível.

Dias Sobrinho $(2003,2004)$ é um dos autores mais destacados na utilização do conceito Estado avaliador para compreender as metamorfoses da relação entre Estado e sociedade civil com relação à educação superior. 0 autor aponta para o papel técnico, ético e político que desempenha a avaliação, de grande impacto nas transformações e reformas da educação superior (e da própria sociedade).

Dias Sobrinho diferencia dois paradigmas relacionados ao exercício da função avaliativa: um paradigma que vincula a avaliação à lógica de mercado, de caráter meritocrático e desenvolvido visando ao controle lno qual a universidade é vista como uma empresa, num vasto mercado de formação, e as instituições que não apresentam resultados satisfatórios devem ser punidas); e outro paradigma, de caráter formativo, que pensa a avaliação como um bem público, produtor de sentidos (no qual a universidade é vista como formadora de cidadãos e produtora de prioridades de pesquisa e currículos). A preocupação do autor está vinculada ao exercício autoritário da avaliação dos programas e instituições universitárias por parte do Estado, vivenciada na Europa e também na América Latina.

O controle pelo Estado tem assumido a função de uma tecnologia de poder, fiscalização e até intervenção estatal sobre indivíduos, instituições e sistema educacional. Os sentidos da avaliação são amplos e complexos, envolvendo determinação das variáveis estudadas, dos modos e condições de produção, da difusão que é dada aos resultados, do tratamento dado pela mídia, dos sistemas de premiação e financiamento atrelados aos resultados, do envolvimento ético e político dos especialistas vinculados ao poder, entre outros aspectos relevantes.

Projetos de diversa natureza e autoria foram cogitados para o desenvolvimento da avaliação da educação superior brasileira, e autores como Palharini (2004), Queiroz (2011) e Sousa (2011) sistematizaram os conflitos em torno das propostas governamentais em diferentes períodos da história recente, especialmente no que se refere à autodeterminação, autonomia universitária e autoavaliação. 0 exercício da avaliação institucional como mecanismo para controlar ou limitar a autonomia universitária foi amplamente estudado por Cunha $(1999,2006)$.

Para Dourado, Oliveira e Cattani (2003), a educação superior no Governo FHC foi caracterizada pela diversificação e diferenciação de instituições e cursos, expansão acelerada de vagas no setor privado e ajustamento das instituições públicas a uma perspectiva gerencialista e produtivista, sob a compreensão de que a universidade deveria formar profissionais e gerar tecnologias a serviço das necessidades do capital produtivo, subordinando sua produção acadêmica 
às demandas do mercado. Essa reconfiguração da educação superior brasileira teria acontecido, em grande medida, como consequência da implementação de um amplo sistema de avaliação, que

produziu uma classificação dos cursos e das instituições como forma de assegurar a pretensa qualidade de ensino. 0 parâmetro do controle de qualidade no mercado acadêmico é, portanto, o consumidor dos serviços e produtos universitários. É o consumidor, bem informado, quem decide e faz a escolha, em função do que pode consumir. (Dourado; Oliveira; Cattani, 2003, p. 25, grifos dos autores)

O Estado brasileiro concentrou seus esforços na elaboração de estratégias para diminuir sua participação no financiamento e no fornecimento direto de serviços educacionais, mas exercendo cada vez mais o controle dos resultados dos serviços educacionais. Esse tipo de controle é incentivado por alguns organismos internacionais que atuam como financiadores de políticas, os quais, sob o pretexto de ajuda financeira, interferem nas políticas nacionais de educação, além de agirem como agentes na globalização do conhecimento e do capitalismo. Essa situação implica a adoção de uma cultura de gestão nos moldes empresariais e, ao mesmo tempo, a criação de mecanismos de responsabilização social.

Oliveira, Fonseca e Amaral (2006) retomam a questão dos impactos que diferentes procedimentos e modalidades de avaliação da educação superior trazem para a própria cultura acadêmica: a definição do trabalho docente e o plano de carreira, a gestão das instituições de educação superior, as definições curriculares e, em definitivo, a estruturação do campo da educação superior. Os autores avaliam o sentido político e ético que ancora as diretrizes teórico-conceituais da avaliação no Brasil, ressaltando que a questão nuclear a ser respondida é esta: para que se quer avaliar? Os autores argumentam que a avaliação deveria servir ao propósito de contribuir para a formulação de juízos equilibrados e para a tomada de decisões que incidirão diretamente sobre o aperfeiçoamento do processo de desenvolvimento das IES, tendo em vista a qualidade do trabalho acadêmico.

\section{Sintetizando}

A literatura científica aponta que o Estado brasileiro se relaciona de diversas maneiras com as políticas públicas de educação: financia (total ou parcialmente, segundo os níveis do sistema educacional) as políticas educacionais por meio de diversos programas e ações (por exemplo, construção de edifícios, aquisição de equipamentos, salários dos docentes universitários, assistência estudantil, apoio à pesquisa, apoio à participação em eventos, entre outros); regula o mercado educacional (por exemplo, credenciamento e recredenciamento de instituições privadas por meio da Secretaria de Educação Superior - Sesu); e, finalmente, 
controla o desempenho institucional (por exemplo, as avaliações da Coordenação de Aperfeiçoamento de Pessoal de Nível Superior - Capes sobre a criação e o funcionamento de programas de pós-graduação no Brasill).

Em linhas gerais, as produções localizadas apontam para um fortalecimento da regulação e da avaliação (segunda e terceira maneira de relação indicadas), em detrimento da participação relativa do Estado no financiamento (primeira). As produções também analisam o duplo caráter (técnico e político) da avaliação educacional, ressaltam a instauração de um Estado mínimo no que diz respeito à responsabilidade pela promoção e manutenção de políticas educacionais, e a paralela instauração de um Estado máximo no que se refere ao controle e à avaliação do desempenho institucional - repare-se: do desempenho institucional, e não do desempenho da política educacional como um todo.

Por isso, com maior facilidade o foco da discussão atual sobre políticas educacionais se distancia dos pontos centrais dos planos de educação ou de governo, como, por exemplo, a diminuição da desigualdade social, que não é considerada ao avaliar as instituições. A avaliação não é um processo neutro, mas um processo essencialmente político. As instituições são avaliadas a partir do princípio meritocrático que impera na educação formal ou escolarizada, ou nos sistemas de ciência e tecnologia, e não de outros princípios fundamentais à democracia, quais sejam os de justiça social e equidade.

\section{Referências}

AFONSO, Almerindo Janela. Estado, mercado, comunidades e avaliação: esboço para uma rearticulação crítica. Educação e Sociedade, v. XX, n. 69, dez. 1999, p. 139-164.

Reforma do Estado e Políticas Educacionais: Entre a Crise do EstadoNação e a Emergência da Regulação Supranacional. Educação e Sociedade, v. XXII, n. 75, p. 15-32, Ago. 2001.

AGLIETTA, Michel. Régulation et crisis du capitalisme. 2 ed. Paris: Calmann - Lévy, 1982.

ALLAL, Linda. Avaliação das Aprendizagens. In: VAN ZANTEN, Agnes (Coord.) (2011). Dicionário de Educação. Petrópolis/RJ: Vozes, 2011, p. 71- 74.

BRUNNER, José Joaquín. Universidad, sociedad y Estado en los 90. Nueva Sociedad, n. 107, p. 70-76, Mayo-Junio. 1990.

. Dr. Prometheus visits Latinamerica. In: Enders, Jürgen; van Vught, Frans (Eds.), Towards a cartography of higher education policy change - A Festschrift in Honour of Guy Neave. Enschede: University of Twente, Center for Higher Education Policy Studies (CHEPS), 2007, p. 265-272.

5. Ver análise original em Yannoulas; Souza e Assis, 2009. 
CARVALHO, Luis Miguel. Governando a Educação pelo Espelho do Perito: Uma Análise do Pisa como Instrumento de Regulação. Educação e Sociedade, v. 30, n. 109, p. 1009-1036, set.-dez. 2009.

Multirregulação, comparações internacionais e conhecimento pericial: interpelando o PISA como provedor de conhecimentos e políticas. In: OLIVEIRA, Dalila Andrade; DUARTE, Adriana (Orgs.). Políticas Públicas e Educação: regulação e conhecimento. Belo Horizonte: Fino Traco, 2011. p.183-206.

CHATEL, Elisabeth. Avaliação (Teorias da). In: VAN ZANTEN, Agnes (Coord.). Dicionário de Educação. Petrópolis/RJ: Vozes, 2011. p. 67-71.

CUNHA, Luiz Antônio. Avaliação universitária na América Latina. In: FREITAS, Marcos Cezar de (Org.) A reinvenção do futuro. 2 ed. São Paulo: Cortez, 1999. p. 143-166.

Autonomia Universitária: teoria e prática. In: VESSURI, Hebe (Comp.) Universidad e Investigación Científica: Convergencias y tensiones. Buenos Aires: CLACSO, 2006. p. 13-31.

DALE, Roger. A sociologia da educação e o Estado após a globalização. Educação e Sociedade, v.31, n.113, p. 1099-1120. 2011.

DIAS SOBRINHO, José. Avaliação, Políticas Educacionais e Reformas da Educação Superior. São Paulo: Editora Cortez, 2003.

Avaliação ética e política em função da educação como direito público ou como mercadoria? Educação e Sociedade, v.25, n. 88, p. 703-725, out. 2004.

DOURADO, Luiz Fernandes; CATANI, Afrânio Mendes; OLIVEIRA, João Ferreira. Transformações Recentes e Debates Atuais no Campo da Educação Superior no Brasil. In: _. (Orgs.). Políticas e gestão da educação superior. São Paulo: Xamã / Goiânia: Alternativa, 2003. p. 17-30.

DUARTE, Adriana. Tendências das Reformas Educacionais na América Latina para a Educação Básica nas décadas de 1980 e 1990. In: FARIA FILHO, Luciano Mendes et al.. Reformas Educacionais no Brasil: Democratização e qualidade da escola pública. Belo Horizonte: Maza Edições, 2010. p. 161-185.

Políticas educacionais e trabalho docente na atualidade. In: OLIVEIRA, Dalila Andrade; DUARTE, Adriana (Orgs.) (2011), Políticas Públicas e Educação: regulação e conhecimento. Belo Horizonte: Fino Traço, 2011. p.161-182.

DUPRIEZ, Vincent. Autonomia dos Estabelecimentos. In: VAN ZANTEN, Agnes (Coord.). Dicionário de Educação. Petrópolis/RJ: Vozes, 2011. p. 60-62.

DUTERCQ, Yves. Administração da Educação. In: VAN ZANTEN, Agnes (coord.) Dicionário de Educação. Petrópolis/RJ: Vozes, 2011. p. 21 - 25.

ELLIOTT, John. La reforma educativa en el Estado Evaluador. Perspectivas, v. XXXII, n 3, p. 1-20. Septiembre, 2002.

ENDERS, Jürgen; VAN VUGHT, Frans (Eds.) Towards a cartography of higher education policy change. A Festschrift in Honour of Guy Neave. Enschede: University of Twente, Center for Higher Education Policy Studies (CHEPS), 2007.

GREEN, Andy (2011). Estado e Educação. In: VAN ZANTEN, Agnes (Coord.). 
Dicionário de Educação. Petrópolis/RJ: Vozes, 2011. p. 364-369.

HOUAISS, Antonio; VILLAR, Mauro de Salles. Dicionário Houaiss da língua portuguesa. Rio de Janeiro: Objetiva, 2001.

KRAWCZYK, Nora; VIEIRA, Vera Lúcia. Uma perspectiva histórico-sociológica da Reforma Educacional na América Latina. Argentina, Brasil, Chile e México nos anos 1990. 2 ed. Brasília/DF: Liberlivro, 2002.

MAROY, Christian. Em direção a uma regulação pós-burocrática dos sistemas de ensino na Europa? In: OLIVEIRA, Dalila Andrade; DUARTE, Adriana (Orgs.). Políticas Públicas e Educação: regulação e conhecimento. Belo Horizonte: Fino Traço, 2011b. p. 19-46.

MAROY, Christian, Regulação dos Sistemas Educacionais. In: VAN ZANTEN, Agnes (Coord.). Dicionário de Educação. Petrópolis/RJ: Vozes, 2011b. p. 688-693.

NEAVE, Guy. On the cultivation of quality, efficiency and enterprise: An overview of recent trends in higher education in Western Europe, 1986-1988. European Journal of Education, v 23, n 1/2, p. 7-23. 1988.

NEAVE, Guy. Reconsideración del estado evaluador. In: NEAVE, Guy, Educación superior: historia y política. Estudios comparativos sobre la universidad contemporánea, Barcelona, Gedisa, 2001. p. 211-242.

NEAVE, Guy; VAN VUGHT, Frans. (Comps.). Prometeo Encadenado. Estado y Educación Superior en Europa. Barcelona: Gedisa Editorial, 1993.

OLIVEIRA, Dalila Andrade. Regulação das Políticas Educacionais na América Latina e os Trabalhadores Docentes. Educação e Sociedade, Campinas, v. 26, n. 92, Especial, p. 753-775, out. 2005.

As políticas públicas em educação e a pesquisa acadêmica. In: OLIVEIRA, Dalila Andrade; DUARTE, Adriana (Orgs.). Políticas Públicas e Educação: regulação e conhecimento. Belo Horizonte: Fino Traço, 2011. p. 71-90.

OLIVEIRA, João Ferreira de; FONSECA, Marília; AMARAL, Nelson Cardoso. Avaliação, desenvolvimento institucional e qualidade do trabalho acadêmico, Educar em Revista, n. 28, p. 71-87. 2006.

PALHARINI, Francisco de Assis. Revista Avaliação: pólo de resistência da avaliação institucional autônoma e democrática. In: MANCEBO, Deise; FAVERO, Maria de Lourdes (Orgs.) Universidade: políticas, avaliação e trabalho docente. Perdizes/SP: Cortez Editora, 2004. p. 189-210.

PONS, Xavier. Avaliação das Políticas Educativas. In: VAN ZANTEN, Agnes (Coord.). Dicionário de Educação. Petrópolis/RJ: Vozes, 2011. p. 74-77.

QUEIROZ, Kelli Consuelo Almeida de Lima. Eu avalio, tu avalias, nós nos avaliamos? Uma experiência proposta pelo Sinaes. Campinas/SP: Autores Associados, 2011. SOUSA, José Vieira de. Educação Superior no Brasil: Expansão, Avaliação e Tendências na Formação de Professor. In: CUNHA, Célio da; SOUSA, José Vieira de; SILVA, Maria Abádia da (Orgs.) Políticas Públicas de Educação na América Latina: lições aprendidas e desafios. Campinas/SP: Autores Associados, 2011. p. 193-240. SOUSA, Sandra Maria Zakia Lian. Possíveis Impactos das Políticas de Avaliação no 
Currículo Escolar. Cadernos de Pesquisa, n. 119, p. 175-190, jul. 2003.

SOUSA, Sandra Maria Zakia Lian.; OLIVEIRA, Romualdo Portela. Políticas de Avaliação da Educação e Quase Mercado no Brasil. Educação e Sociedade, Campinas, v. 24, n. 84, p. 873-895, set. 2003.

VACCAREZZA, Leonardo Silvio. Autonomía universitaria, reformas y transformación social. In: VESSURI, Hebe (Comp.) Universidad e Investigación Científica: Convergencias y tensiones. Buenos Aires: CLACSO, 2006. p. 33-49.

VAN ZANTEN, Agnes. Políticas Educativas. In: VAN ZANTEN, Agnes (Coord.). Dicionário de Educação. Petrópolis/RJ: Vozes, 2011. p. 640-645.

YANNOULAS, Silvia; SOUZA, Camila Rosa; ASSIS, Samuel Gabriel. Políticas Educacionais e o Estado Avaliador: uma relação conflitante. Sociedade em Debate, v. 15, n. 2, p. 55-68, jul-dez. 2009.

Recebido em outubro de 2012

Aprovada em janeiro de 2013

Silvia Cristina Yannoulas é professora do Departamento de Serviço Social e do Programa de Pós-graduação em Política Social da Universidade de Brasília (SER/ UnB) e líder do Grupo de Pesquisa Trabalho, Educação e Discriminação (TEDis). Email: silviayannoulasवunb.br

Talita Santos de Oliveira é formada em Serviço Social pela Universidade de Brasília - UnB. Mestranda do Programa de Pós-graduação em Política Social da UnB. Membro do Grupo de Pesquisa Trabalho, Educação e Discriminação - TEDis da UnB. Email: talitaoliveiradagmail.com 